\title{
Effect of Soil Density and Electrode Material on the Electrokinetic Removal of Pb(II) from Contaminated Silt Soil
}

\author{
Gang $\mathrm{Li}^{1}$, Chongkun Chen ${ }^{1}$, Jia Liu ${ }^{2, *}$, Yao Zhang ${ }^{1}$, Shuai $\mathrm{Li}^{3}$ \\ ${ }^{1}$ Shaanxi Key Laboratory of Safety and Durability of Concrete Structures, Xijing University, Xi'an, \\ Shaanxi 710123, China; \\ ${ }^{2}$ School of Geological Engineering and Geomatics, Chang'an University, Xi'an, Shaanxi 710054, \\ China; \\ ${ }^{3}$ State Key Laboratory of Coastal and Offshore Engineering, Dalian University of Technology, Dalian, \\ Liaoning 116024, China. \\ *E-mail: 15929935077@163.com
}

Received: 19 July 2021/ Accepted: 3 September 2021 / Published: 10 October 2021

\begin{abstract}
With the increase in industrial $\mathrm{Pb}$-containing products, $\mathrm{Pb}$ pollution is gradually accumulating in the soil, leading to the degradation of soil quality and damage to human health. To find an efficient and environmental method for the remediation of $\mathrm{Pb}$-contaminated silt soil, electrokinetic remediation (ER) was carried out with different soil densities and electrode materials, and the variation laws of the current $(I)$, potential $(U), \mathrm{pH}$, removal efficiency $(R)$, and energy consumption $(E)$ during the ER process were investigated. The results showed that as the ER time $(t)$ increased, $I$ showed a trend of increasingdecreasing-increasing, while $U$ showed a trend of decreasing-increasing-decreasing. Soil density had a great effect on the soil $\mathrm{pH}$, while the electrode material had a great impact on the catholyte $\mathrm{pH}$. Both $\mathrm{Pb}$ (II) $R$ and $E$ decreased with increasing soil density. The maximum $\mathrm{Pb}$ (II) $R$ reached $98.13 \%$ with a unit $E$ of $1.34 \mathrm{~W} \cdot \mathrm{h} / \mathrm{mg}$. The $\mathrm{Pb}(\mathrm{II}) R$ obtained with different electrode materials followed the order of ruthenium-iridium coated titanium mesh $>$ rhodium-iridium coated titanium mesh $>$ ruthenium-iridium coated titanium plate, indicating that the electrode of ruthenium-iridium coated titanium mesh had the best removal effect in the ER of the $\mathrm{Pb}$ (II)-contaminated silt soil. The research results can provide a reference for ER projects in $\mathrm{Pb}(\mathrm{II})$-contaminated silt soil areas.
\end{abstract}

Keywords: Electrokinetic remediation; silt soil; density; electrode; removal efficiency

\section{$\underline{\text { FULL TEXT }}$}

(C) 2021 The Authors. Published by ESG (www.electrochemsci.org). This article is an open access article distributed under the terms and conditions of the Creative Commons Attribution license (http://creativecommons.org/licenses/by/4.0/). 